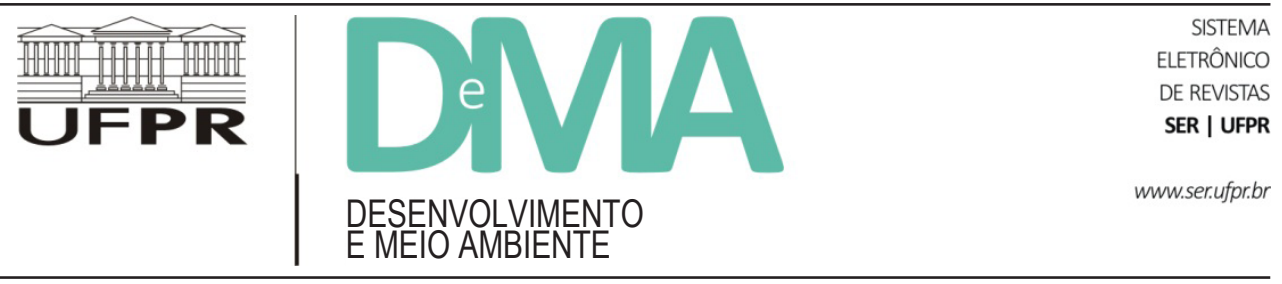

\title{
A proteção jurídica dos fragmentos florestais urbanos: um estudo da paisagem e da legislação ambiental e urbanística da cidade de Manaus
}

\section{Legal Protection of Urban Forest Fragments: Landscape and Environmental and Urbanistic Law of Manaus}

\author{
Stephany Anry KUDO ${ }^{1 *}$, Henrique dos Santos PEREIRA ${ }^{1}$, Suzy Cristina Pedroza da SILVA ${ }^{1}$ \\ ${ }^{1}$ Programa de Pós-Graduação em Ciências do Ambiente e Sustentabilidade na Amazônia (PPGCASA), Universidade Federal do Amazonas \\ (UFAM), Manaus, AM, Brasil. \\ *E-mail de contato: anrykudo@hotmail.com
}

Artigo recebido em 23 de agosto de 2015, versão final aceita em 9 de maio de 2016.

RESUMO: Devido à expansão e ao adensamento das malhas urbanas, a vegetação e outros componentes naturais acabam tornando-se os elementos mais vulneráveis da paisagem urbana. A permanência desses componentes requer não apenas que sua existência seja prevista no planejamento urbano, mas também que um arcabouço legal lhes confira uma proteção jurídica efetiva. Este estudo teve como objetivo avaliar a aplicabilidade das normas jurídicas na proteção dos fragmentos florestais urbanos (FFUs) na cidade de Manaus, a partir de uma análise dos instrumentos legais ambientais e urbanísticos nas três esferas de governo. Verificou-se que nas esferas federal e estadual não há instrumentos específicos de proteção para os FFUs. Ainda que a legislação municipal de Manaus contenha referências aos FFUs como áreas protegidas, constatou-se que o poder público municipal não dispõe de instrumentos legais que garantam de fato a proteção desses espaços como tais. Os resultados sugerem que um FFU passa a gozar de proteção jurídica efetiva somente se afetado como unidade de conservação, quando seus limites, dominialidade, destinação e gestão local passam a ser claramente determinados por ato do poder público.

Palavras-chave: florestas urbanas; áreas verdes; unidades de conservação; planejamento urbano.

ABSTRACT: Due to the expansion and densification of urban networks, vegetation and other natural components end up becoming the most vulnerable elements of the urban landscape. The permanence of these components require not only that their existence must be provided for in urban planning, but also that the legal framework which gives them legal protection should be effective. This study aims to evaluate the applicability of legal rules in protecting urban forest fragments (UFFs) in Manaus, analyzing the environmental and urban legal instruments from the three levels of government. It was found that at the federal and state levels there are no specific instruments of protection for UFFs. Although the municipal law of Manaus contains references to UFFs as protected areas, 
it was found that the municipal government has no legal instruments to truly ensure the protection of these areas as such. The results suggest that an UFF would benefit from effective legal protection only if affected as Conservation Unit, when its limits, dominion, destination and management plans are clearly defined by a governmental act.

Keywords: urban forests; urban green areas; conservation unit; urban planning.

\section{Introdução}

A presença da vegetação nas cidades tem sido considerada um sinônimo de qualidade de vida, ao mesmo tempo em que o "verde" é o elemento mais frágil da paisagem urbana, uma vez que as coberturas vegetacionais sofrem diretamente os efeitos das ações antrópicas decorrentes das pressões da urbanização e do adensamento populacional (Alvarez, 2004).

Embora as cidades venham experimentando diferenciados ritmos de crescimento populacional, determinados por estímulos e razões diversas, o resultado é quase sempre o mesmo. Muitas vezes com a chancela do Poder Público, seus habitantes acabam por estabelecer formas de utilização social e ambientalmente inadequadas do território urbano, além de degradarem áreas que, em princípio, teriam uma função muito mais ambiental e paisagística do que uma destinação residencial, como é o caso dos fragmentos florestais urbanos (Maquiné, 2006). Os fragmentos florestais são áreas cobertas com vegetação e que se constituem como resquícios de vegetação natural circundados por uma matriz urbana (Melo et al., 2011). Esses fragmentos são considerados recursos preciosos para a melhoria da qualidade de vida nas cidades, pois o uso da vegetação ameniza os impactos causados pela ação antrópica.

Manaus, capital do Amazonas, é a principal cidade da Amazônia ocidental brasileira. Um exemplo de zona urbana desenvolvida no meio da flo- resta ligada à sua bacia de drenagem. Circundada e entremeada por um patrimônio ambiental valoroso, a cidade e seus habitantes se ressentem por causa das degradações ambientais causadas pela remoção da floresta e pela poluição dos cursos d'água, com efeitos diretos e negativos sobre a qualidade do ambiente urbano, a biodiversidade e a saúde da população humana. Com o crescimento desordenado da cidade, a floresta foi reduzida a fragmentos em meio a vários bairros e conjuntos residenciais com alta densidade demográfica (Dos Anjos, 2007; Freitas \& Ribeiro, 2007). Em estudo realizado por Gontijo (2008), foram identificados 56 fragmentos distribuídos nas seis zonas administrativas (norte, sul, leste, oeste, centro-sul e centro-oeste) da cidade de Manaus.

Ainda que se reconheça a importância dos fragmentos florestais nos centros urbanos, não é suficiente que esses espaços apenas existam nas várias cidades como "sobras" dos processos de parcelamento do solo. É necessário que haja investimentos na conservação dessas áreas e no planejamento adequado, visando assim ao seu melhor aproveitamento. Para que os fragmentos florestais urbanos (FFUs) se mantenham, é necessária a aplicação de normas ambientais e urbanísticas, com a finalidade de proteção (Ramos, 2005). Assim, os FFUs que restam deveriam ser protegidos, expandidos e conectados - e novas áreas verdes poderiam ser criadas -, tornando-os uma questão prioritária em uma política de gestão ambiental para as cidades (Minks, 2013). 
Nesse aspecto, a avaliação da eficácia dos instrumentos legais aplicáveis na proteção dessas áreas pode contribuir imensamente para o aperfeiçoamento do planejamento e a governança ambiental urbana, de modo a se alcançar a qualidade ambiental, o desenvolvimento socioeconômico sustentável e a conservação da biodiversidade nas cidades.

A eficácia refere-se a uma propriedade que tem um ato legal de produzir, de fato, o resultado desejado (Carli, 2004) e torna-se uma condição necessária, embora não suficiente, para a efetividade da proteção jurídica, para que a sociedade e o ambiente possam usufruir da produção do efeito previsto no texto legal (Freitas, 2002). A discussão aqui proposta não trata, portanto, de averiguar se normas legais são suficientes, mas se as legislações atuais têm o potencial de dar a segurança jurídica necessária para o planejamento e a proteção efetivos dos FFUs. Dessa forma, o presente estudo objetivou avaliar a aplicabilidade das normas jurídicas com a finalidade de proteção dos fragmentos florestais urbanos, na cidade de Manaus, a partir de uma análise dos instrumentos legais ambientais e urbanísticos existentes na doutrina brasileira, principalmente no que diz respeito à legislação municipal, com destaque ao Código Ambiental de Manaus.

\section{Material e Métodos}

A cidade de Manaus está localizada na região central da maior floresta tropical e maior bacia hidrográfica do mundo. Situada na confluência dos rios Negro e Solimões na Amazônia Central, Manaus é cercada por Floresta Ombrófila Densa (Floresta Tropical Úmida) e outros tipos de vegetação, como Formações Pioneiras de Influência Fluvial (vegetação aluvial), Campinas e Campinaranas (IBGE, 2012). Suas coordenadas geográficas são $03^{\circ} 06^{\prime} 07^{\prime}$ 'S e $60^{\circ} 01^{\prime} 30^{\prime \prime} \mathrm{W}$, limitando-se ao norte com o município de Presidente Figueiredo, a leste com Rio Preto da Eva e Itacoatiara, a oeste com Manacapuru e Novo Airão e ao sul com os municípios de Careiro da Várzea ( $3^{\circ} 11^{\prime} 53^{\prime \prime}$ S e $\left.59^{\circ} 52^{\prime} 18^{\prime \prime}\right)$ e Iranduba (3॰10'47's e 60'13'02"').

Sua população em 2010 alcançou 1.802.014 habitantes, correspondendo a $51,72 \%$ da população do Estado do Amazonas, com uma densidade demográfica de 158,06 hab. $/ \mathrm{km}^{2}$. Concentra a maior parcela da economia do Estado que, em 2012, correspondia a $77,7 \%$ do PIB estadual (IBGE, 2012). A malha urbana possui uma área territorial de $483,39 \mathrm{~km}^{2}$, equivalendo a 4,2\% da área do município, dividida em zonas: Norte, Leste, Sul, Oeste, Centro-Sul e Centro-Oeste, com pelo menos 63 bairros oficiais (PMM, 2015).

Nesse contexto, foram selecionados dois FFUs representativos da cidade de Manaus para estudos em escala local: o FFU conhecido como "Fragmento da Ilha", com 12,99 ha, localizado no bairro Planalto, e o FFU "Mundo Novo", com 4,9 ha, no bairro da Cidade Nova (Figura 1).

As análises quantitativas foram baseadas em dados vetoriais e dados raster subsidiados pelo Centro de Ciências do Ambiente (CCA-UFAM), a partir dos fragmentos florestais urbanos, áreas verdes, unidades de conservação e limites municipais. Foram utilizadas imagens Ikonos II, das bandas multiespectrais (2, 3 e 4), de dois fragmentos em Manaus - AM, com imagens capturadas em 2014, cedidas pela Secretaria Municipal de Meio Ambiente - Prefeitura Municipal de Manaus e processadas no programa ENVI 4.6. 


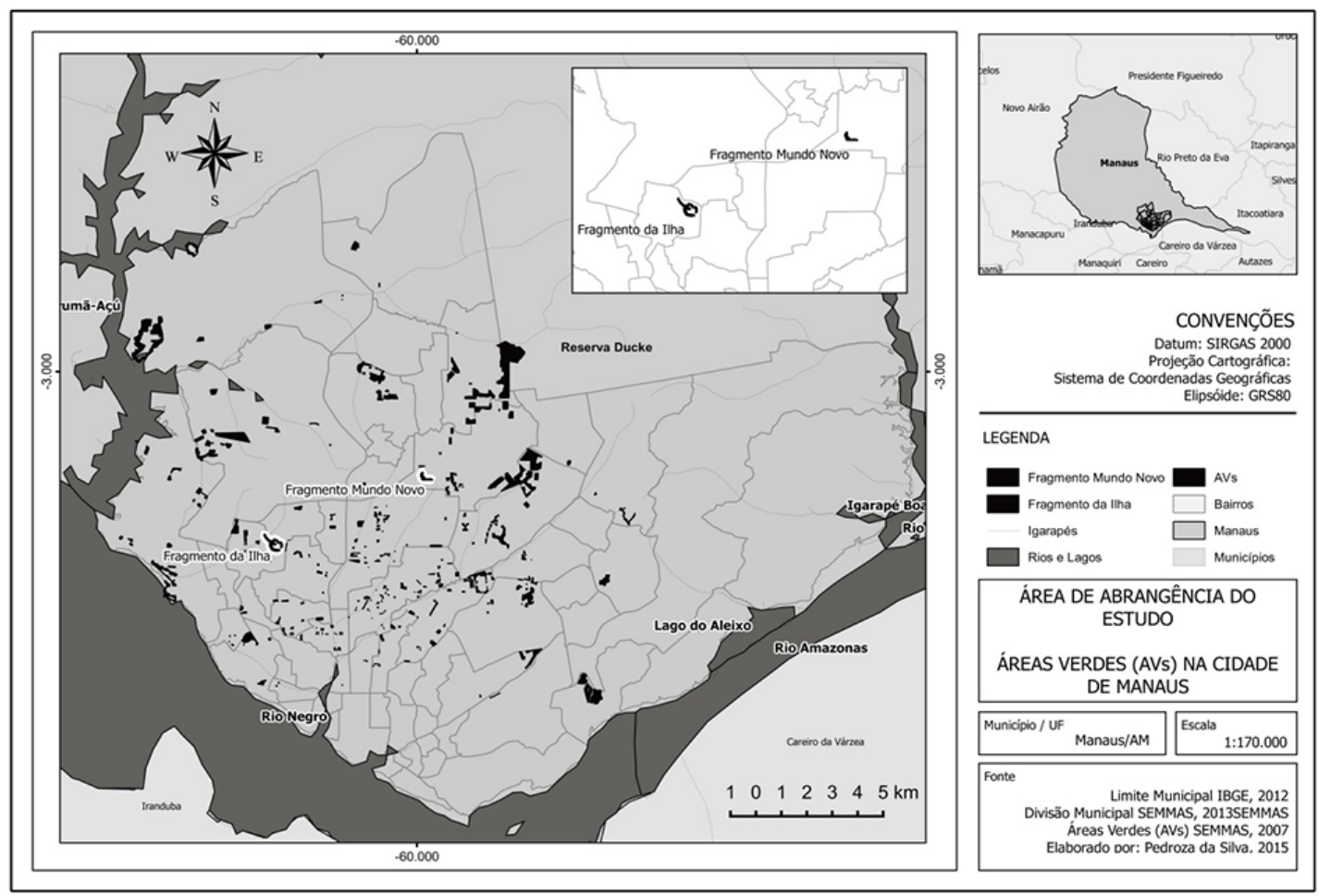

FIGURA 1 - Localização da área de estudo, Manaus-Amazonas.

\section{A proteção dos fragmentos florestais urbanos}

Considerando-se os diversos diplomas legais nacionais, pode-se afirmar que somente a partir de 1980 uma legislação voltada para a questão ambiental começou a ser elaborada no Brasil, tendo como marco inicial a Lei ${ }^{\circ} 6.938$, de 31 de agosto de 1981, que instituiu a Política Nacional do Meio Ambiente (PNMA). Essa política objetiva a preservação, a melhoria e a recuperação da qualidade ambiental propícia à vida, visando assegurar, no país, condições ao desenvolvimento socioeconômico, aos interesses da segurança nacional e à proteção da dignidade da vida humana, e criou o
Sistema Nacional do Meio Ambiente - SISNAMA (Brasil, 1981).

A PNMA já indicava claramente a criação de áreas protegidas como princípio e instrumento da proteção ambiental.

Em seu artigo $2^{\circ}$, a PNMA estabelece seus dez princípios, dentre eles:
Art. $2^{\circ}-[\ldots]$
I - ação governamental na manutenção do equilíbrio ecológico, considerando o meio ambiente como um patrimônio público a ser necessariamente assegurado e protegido, tendo em vista o uso coletivo;
$[\ldots]$
IV - proteção dos ecossistemas, com a preservação de áreas representativas. 
Quanto aos instrumentos previstos no artigo $9^{\circ}$, verifica-se que:

Art. $9^{\circ}$ - São instrumentos da Política Nacional do Meio Ambiente:

[...]

VI - a criação de espaços territoriais especialmente protegidos pelo Poder Público federal, estadual e municipal, tais como área de proteção ambiental, de relevante interesse ecológico e reservas extrativistas.

A Constituição Federal de 1988 foi fruto da evolução das discussões sobre a questão ambiental e é considerada um grande avanço no ordenamento jurídico nacional ao dedicar um capítulo específico ao meio ambiente. No caput do artigo 225, há uma norma-princípio enunciativa do direito de todos ao meio ambiente ecologicamente equilibrado. Para a efetividade desse direito, a Constituição, além de impor de forma genérica o dever tanto da coletividade quanto do Poder Público de preservar o meio ambiente, especificou alguns deveres a este último (Meira, 2008; Pereira \& Scardua, 2008).

Tratando-se das questões ambientais envolvendo a flora, como é o caso dos fragmentos florestais urbanos, a competência para a sua proteção e do meio ambiente em geral é comum à União, aos Estados, ao Distrito Federal e aos Municípios, conforme o que determina o art. 23, VI e VII, da Constituição Federal de 1988.

Art. 23 - É competência comum da União, dos Estados e do Distrito Federal e dos Municípios:

[...]

VI - proteger o meio ambiente e combater a poluição em qualquer de suas formas;

VII - preservar as florestas, a fauna e a flora.

Observa-se que o compromisso e o dever de proteger o meio ambiente, em especial as florestas (fragmentos florestais), é determinado a todos os entes, no entanto, este dever não se distribui igualitariamente entre os entes federados. Assim como os demais entes, os municípios são dotados da atribuição administrativa ambiental, no entanto, carecem de competência legislativa em se tratando de certos recursos ambientais. Nesse sentido, a competência legislativa, ou seja, o poder de legislar sobre a questão ambiental, é determinada no artigo 24, inciso VI, que excetua o Município:

Art. 24 - Compete à União, aos Estados e ao Distrito Federal legislar concorrentemente sobre:

VI - florestas, caça, pesca, fauna, conservação da natureza, defesa do solo e dos recursos naturais, proteção do meio ambiente e controle da poluição.

No entanto, apesar de não prevista expressamente no artigo 24, a competência dos municípios em legislar quanto à questão ambiental pode ser subentendida no artigo 30, incisos I e II, do texto constitucional, que determinam que:

Art. 30 - Compete aos Municípios:

I - legislar sobre assuntos de interesse local;

II - suplementar a legislação federal e a estadual no que couber.

Portanto, o Município também possuiria, em matéria ambiental, a competência administrativa em comum com a União e o Estado e também a competência legislativa concorrente com esses entes federativos. Dessa maneira, todas as questões que dizem respeito ao meio ambiente urbano são de interesse da população local, logo, entende-se que é papel do Município agir nas questões de natureza ambiental dentro do seu espaço territorial, como é o caso em especial dos fragmentos florestais urbanos, visto que estão contidos dentro de limites territo- 
riais das cidades e cuja preservação é de interesse, fundamentalmente, da população local.

A proteção ambiental dos FFU requer que estes sejam administrados pelo poder público como Espaços Territoriais Especialmente Protegidos (ETEP). Os ETEPs regulamentados pela legislação federal brasileira são: área de preservação permanente, reserva legal, sítio arqueológico, terra indígena, unidade de conservação, área verde, dentre outros. Logo, os ETEPs constituem o "gênero", do qual unidades de conservação, demais áreas protegidas e, eventualmente, os FFUs são as “espécies”.

Nota-se que a PNMA de 1981 já exemplificava como espaços territoriais algumas categorias de unidades de conservação. Segundo Filho (2011), os espaços territoriais especialmente protegidos consistem nas áreas geográficas de significativa relevância ambiental, às quais o Poder Público comporta o dever de definir, criar, gerenciar e proteger, objetivando a proteção das espécies, a conservação dos recursos naturais e o bem-estar das populações habitantes desses perímetros. Brandão (2012, p. 229), os conceitua como porções públicas ou privadas do território brasileiro dotadas de atributos ambientais relevantes que justifiquem sua especial proteção pelo Poder Público e pela coletividade.

Somente em 2000, quando foi editada a Lei ${ }^{\circ}$ 9.985, de 18 de julho, é que se instituiu o Sistema Nacional de Unidades de Conservação, o SNUC. A referida lei determina que unidade de conservação seja o "espaço territorial e seus recursos ambientais, incluindo as águas jurisdicionais, com características naturais relevantes, legalmente instituído pelo Poder Público, com objetivos de conservação e limites definidos, sob regime especial de administração, ao qual se aplicam garantias adequadas de proteção". Por constitui-se de um espaço territorial com limites definidos, conforme o artigo $2^{\circ}$ do SNUC, a condição de Unidade de Conservação pode conferir importante proteção jurídica a um fragmento florestal urbano, visto que unidades de conservação são espaços criados e não apenas reconhecidos por seus atributos naturais, como é o caso das áreas de preservação permanente e do fragmento florestal urbano como espécies de área protegida, como será visto mais adiante.

Considerando-se a expansão urbana e os benefícios que a vegetação proporciona para uma melhor qualidade de vida à população, tem-se o motivo de uma especial atenção voltada para as florestas urbanas e as áreas verdes em geral, dentro dos espaços ao redor da população residente. Assim, toda e qualquer atividade que envolva o uso do solo, especialmente o solo urbano, deve atender a requisitos e instrumentos que possibilitem a sua administração (Matias, 2006). Em se tratando de áreas urbanas, as formações vegetacionais estão mais bem associadas ao conceito de área verde. As áreas verdes de uma cidade incluem todos os espaços que possuem cobertura vegetal natural ou implantada, como as áreas de preservação permanente, parques públicos, praças e áreas verdes destinadas à recreação pela legislação competente (Abreu \& Oliveira, 2004). Ao se tratar de definição jurídica, o termo área verde possui um conceito legal de acordo com a atual Lei Florestal, a Lei $n^{\circ}$ 12.651 de 25 de maio de 2012 .

Art. $3^{\circ}$ - Para os efeitos desta Lei, entende-se por:
XX - área verde urbana: espaços, públicos ou priva-
dos, com predomínio de vegetação, preferencialmente
nativa, natural ou recuperada, previstos no Plano
Diretor, nas Leis de Zoneamento Urbano e Uso do
Solo do Município, indisponíveis para construção de
moradias, destinados aos propósitos de recreação, la-
zer, melhoria da qualidade ambiental urbana, proteção
dos recursos hídricos, manutenção ou melhoria pai-
sagística, proteção de bens e manifestações culturais. 
Embora um conceito legal específico de fragmento florestal urbano não figure na legislação federal vigente, subentende-se que um fragmento pode ser definido também como área verde, considerando que o inciso XX destaca quanto à vegetação "preferencialmente nativa", visto que um fragmento florestal urbano é predominantemente de vegetação nativa. Uma das novidades da lei florestal é que a mesma confere competência aos Municípios para a criação de áreas verdes fora dos loteamentos habitacionais, a exemplo do artigo 26, inciso VI, do Estatuto da Cidade, a Lei ${ }^{\circ} 10.257$, de 10 de julho de 2001 (Brandão, 2012, p. 193).

Art. 26 - O direito de preempção será exercido sempre que o Poder Público necessitar de áreas para:

VI - criação de espaços públicos de lazer e áreas verdes;

VII - criação de unidades de conservação ou proteção de outras áreas de interesse ambiental.

Em se tratando dessa lei urbanística federal, ao avocar o direito de preempção, verifica-se o evidente interesse do legislador federal em definir por meio do Estatuto das Cidades, a Lei $\mathrm{n}^{\mathrm{o}} 10.257$, de 10 de julho de 2001, um mecanismo de proteção ao meio ambiente urbano com a inclusão, dentre suas finalidades, da criação de "espaços públicos de lazer e áreas verdes" e da criação de "unidades de conservação ou proteção de outras áreas de interesse ambiental", conforme determinado no art. 26, incisos VI e VII.

Os FFUs também podem estar associados a Áreas de Preservação Permanente (APP) localizadas no interior da malha urbana. A definição das APPs deriva de instrumentos legais específicos. A referência a Áreas de Preservação Permanente situadas em zonas urbanas figura dentre as mudanças introduzidas pela Lei Florestal n 12.651 de 2012.
De acordo com a referida lei, a APP é definida como uma “área protegida, coberta ou não, por vegetação nativa, cuja função ambiental é preservar os recursos hídricos, a paisagem, a estabilidade geológica, a biodiversidade, facilitar o fluxo gênico de fauna e flora, proteger o solo e assegurar o bem-estar das populações humanas" (Art. $3^{\circ}$, II). O artigo $4^{\circ}$ da Lei $n^{\circ} 12.651 / 2012$ lista as áreas consideradas Áreas de Preservação Permanente, deixando claro na redação do caput do referido artigo que elas podem estar localizadas não somente em zonas rurais, mas também em zonas urbanas.

Trazendo o objeto deste estudo à luz da lei florestal federal, considera-se que esses remanescentes florestais urbanos, por lei ou por ato do Poder Público, podem também vir a ser considerados, em certas situações, como APP. No entanto, eventualmente, quaisquer outras porções do FFU que não se enquadrarem nos critérios definidores de uma APP não estariam protegidas. Dessa forma, fragmentos maiores, em áreas planas ou distantes de cursos d'água, não estariam protegidos e as únicas florestas nativas remanescentes nas cidades seriam aquelas localizadas em APP.

\section{Resultados e discussão: a proteção dos fragmentos florestais urbanos no município de Manaus}

O município de Manaus conta com um Código Ambiental, instituído pela Lei Municipal n ${ }^{\circ} 605$ de 24 de julho de 2001. Este se apresenta como um instrumento jurídico destinado à defesa do meio ambiente na cidade. Na parte geral do Código Ambiental de Manaus (CAM) são estabelecidas as diretrizes básicas, como princípios, objetivos e instrumentos. $\mathrm{O}$ artigo $3^{\circ}$ enumera alguns dos objetivos da Política Municipal Ambiental, dentre eles: 
Art. $3^{\circ}$ - São objetivos da Política Municipal de Meio Ambiente:

$[\ldots]$

$\mathrm{X}$ - cuidar dos bens de interesse comum a todos: os parques municipais, as áreas de proteção ambiental, as zonas ambientais, os espaços territoriais especialmente protegidos, as áreas de preservação permanente e as demais unidades de conservação de domínio público e privado.

É a partir desse Código Ambiental que o termo "fragmento florestal urbano" surge no ordenamento jurídico municipal como conceito previsto no artigo $5^{\circ}$, XVIII:

Art. $5^{\circ}$ - São os seguintes os conceitos gerais para fins e efeitos deste Código:

$[\ldots]$

XVIII - fragmentos florestais urbanos: são áreas remanescentes de vegetação nativa situadas dentro do perímetro urbano do Município, em propriedade pública ou privada, que desempenham um papel na manutenção da qualidade do meio ambiente urbano.

Outro momento em que os fragmentos são abordados no Código Ambiental de Manaus é no inciso IV do Artigo 31, que trata dos espaços territoriais especialmente protegidos, assim dispondo:

Art. 31 - São espaços territoriais especialmente protegidos:

I - as áreas de preservação permanente;

II - as unidades de conservação;

III - as áreas verdes;

IV - os fragmentos florestais urbanos;

$\mathrm{V}$ - as praias, as ilhas, as cachoeiras, a orla fluvial e os afloramentos rochosos associados aos recursos hídricos. (Grifo nosso).

Segundo Ramos (2005), o CAM não criou os espaços territoriais especialmente protegidos, mas elencou cinco categorias destes, conforme o artigo 31, I a V. Como visto, os fragmentos flores- tais urbanos, dependendo de suas características ecológicas e de localização na paisagem, também poderiam ser inseridos como espécies das categorias dos incisos I, II e III. Dessa forma, é necessário analisar-se criteriosamente a legislação municipal para averiguar-se o quão claro foi o legislador ao diferenciar e conceituar essas diferentes espécies de espaços territoriais protegidos urbanos.

De acordo com o artigo $5^{\circ}$, XVII do Código Ambiental de Manaus, áreas verdes são espaços definidos pelo Poder Público Municipal, com base no memorial descritivo dos projetos de parcelamento do solo urbano, constituídos por florestas ou demais formas de vegetação primária, secundária ou plantada, de natureza jurídica inalienável e destinados à manutenção da qualidade ambiental.

Observa-se que a principal diferença entre um FFU e uma área verde é que esta última é resultante de um memorial descritivo, ao contrário dos fragmentos, que são áreas remanescentes e que "sobram" na paisagem urbana. Outro fato a destacar é que o legislador não especifica a condição da cobertura vegetacional de uma área verde, podendo esta ser constituída por floresta primária, secundária ou até mesmo plantada, enquanto os fragmentos florestais são exclusivamente de vegetação nativa. Diante disto, conclui-se que qualquer fragmento florestal urbano poderia vir a ser afetado como área verde, porém, nem toda área verde seria considerada e mantida como um fragmento florestal.

Outro artigo que merece destaque é o art. 38, ao determinar que:

Art. 38 - Os fragmentos florestais urbanos receberão especial atenção do Poder Público Municipal e sua supressão, parcial ou total, somente poderá ocorrer mediante autorização especial do órgão ambiental competente.

Parágrafo Único - O Poder Público Municipal, através de lei, estabelecerá mecanismos de incentivos fiscais 
visando à conservação dos fragmentos florestais urbanos.

Embora evoque a proteção dos fragmentos, este dispositivo torna-se contraditório e falho ao considerar que pode haver supressão de vegetação total ou parcial da floresta urbana, necessitando-se para isso apenas de uma autorização do órgão competente. Além disso, a legislação municipal é omissa, pois não estabelece que FFUs tenham seus limites reconhecidos e tampouco se ocupa em determinar que haja uma destinação aos FFUs.

\subsection{FFUs de Manaus como Unidades de Conservação}

Com respeito às Unidades de Conservação (UCs), o CAM classifica esses espaços em treze categorias, em seu Artigo 33, I - XIII. As únicas categorias de UC municipais que não estão previstas na lei federal do SNUC são o jardim botânico, o horto florestal e o jardim zoológico. Sendo assim, todas as demais categorias, tais como: estação ecológica, reserva biológica, monumento natural, refúgio da vida silvestre, área de relevante interesse ecológico, reserva de desenvolvimento sustentável, área de proteção ambiental, reserva de fauna, reserva particular do patrimônio natural e parque municipal, seriam equivalentes às categorias já previstas pela lei federal.

Outro ponto importante a ser destacado é a possibilidade de o Poder Público Municipal considerar a participação da sociedade na criação das Unidades, conforme o parágrafo único do artigo 36:

Art. $36-[\ldots]$

Parágrafo Único - O Poder Público Municipal pode estimular e acatar iniciativas comunitárias para criação de Unidades de Conservação.
Observa-se que o legislador, ao definir Unidade de Conservação, utiliza o termo genérico "espaço territorial e seus recursos ambientais". Dessa forma, entende-se que os fragmentos florestais urbanos podem atender os requisitos necessários para serem instituídos como UC, desde que apresentem características naturais relevantes, independentemente do tipo de vegetação, e estejam localizados em meio urbano ou não, sejam constituídos por floresta nativa ou cultivada.

Para Arce et al. (2014), parques urbanos são importantes unidades de conservação reconhecidas como indutores de desenvolvimento sustentável nas cidades. No entanto, a criação e a implantação desses parques deflagram vários conflitos socioambientais devido aos diversos interesses sobre a área a ser protegida, principalmente a questão do uso da terra e seus aspectos econômicos e sociais.

Ao analisar o artigo 225 da Constituição Federal, é possível concluir que a participação da sociedade civil é um elemento crucial na gestão das Unidades de Conservação. Apesar da importância nos parques, a participação da população ainda é restrita. E se manifesta, sobretudo, por meio dos conselhos consultivos. Essa participação pode ser definida como uma forma de governança. Para Andrade (2007), os objetivos de governança quanto às Unidades de Conservação (UCs) no Brasil podem ser atingidos por meio da criação e do funcionamento de Conselhos de Gestão. Esses Conselhos são considerados, portanto, como ferramenta importante no processo de gestão de uma UC.

Na década de 90, por exemplo, dois fragmentos florestais urbanos de Manaus tornaram-se unidades de conservação em decorrência da mobilização populacional e foram criados o Parque Estadual Sumaúma e o Parque Municipal do Mindu.

Damasceno et al. (2013) realizaram um estudo sobre FFUs em uma bacia urbana (Igarapé do 
Gigante), com uma área de drenagem de 2.149 ha, abrangendo cinco bairros de Manaus nas zonas oeste e centro-oeste da cidade. Os autores identificaram 134 fragmentos florestais, nos mais diversos tamanhos (0,03 a 260,9 ha), que ainda ocupavam $53 \%$ da área da bacia. Destes, apenas 25 eram maiores que 10 ha. Com diversos cursos d'água, a bacia deveria ter 234 ha protegidos como áreas de preservação permanente (APP), sendo que apenas $63 \%$ dessas áreas ainda estavam recobertas por vegetação do tipo floresta nativa. Este fato indica a pouca efetividade da lei florestal na proteção de florestas em áreas urbanas consolidadas de Manaus. Na mesma bacia, encontram-se quatro UCs municipais no grupo de Uso Sustentável, sendo duas APAs (Parque Linear do Igarapé do Gigante; Parque da Ponta Negra) e duas RPPNs (Águas do Gigante; dos Buritis). Somadas as áreas dessas UCs, elas correspondem a apenas $11 \%$ da área da bacia. $\mathrm{O}$ que significa dizer que no máximo $1 / 10$ dos FFUs da área estaria especialmente protegido.

Até o presente, foram criadas 15 UCs municipais na área urbana de Manaus (Tabela 1). Duas destas (APA do Tarumã/Ponta Negra e APA Adolpho Ducke) estão total ou parcialmente localizadas em áreas rurais ou de transição.

\subsection{FFUs de Manaus como Áreas Verdes}

Em termos de legislação urbanística, é importante destacar o recente Plano Diretor de Manaus, a Lei Complementar $n^{\circ} 002$, de 16 de janeiro de 2014, que faz menção aos espaços territoriais especialmente protegidos como importantes expressões do patrimônio ambiental municipal. Em harmonia com o CAM, o plano diretor também nomeia os fragmentos florestais urbanos, dentre os espaços protegidos, como por exemplo, em seus artigos $6^{\circ}$ e $7^{\circ}$ :

TABELA 1 - Unidades de Conservação Municipais de Manaus localizadas em áreas urbanas.

\begin{tabular}{lcc}
\hline \multicolumn{1}{c}{ Categoria e nome da UC municipal } & Área (ha) & $\begin{array}{c}\text { Ano de } \\
\text { Criação }\end{array}$ \\
\hline Reserva Ecológica Sauim Castanheiras/ Cetas & 95 & 1982 \\
Parque Municipal do Mindu & 40,8 & 1983 \\
Parque Municipal das Nascentes do Mindu & 16,2 & 2006 \\
RPPN Honda & 16,4 & 2006 \\
Corredor Ecológico Urbano do Igarapé do Mindu & 195,27 & 2007 \\
RPPN dos Buritis & 5,5 & 2007 \\
APA do Tarumã/Ponta Negra (*) & $22.698,80$ & 2008 \\
RPPN Águas do Gigante & 35,1 & 2008 \\
Corredor Ecológico Urbano das Cachoeiras do Tarumã & 289,3 & 2009 \\
RPPN Sócrates Bonfim & 230 & 2009 \\
APA Parque Linear do igarapé do Gigante & 155,1 & 2012 \\
APA Parque Ponta Negra & 39,8 & 2012 \\
APA Adolpho Ducke * & $18.240,80$ & 2012 \\
APA UFAM, INPA, ULBRA, Elisa Miranda, Lagoa do Japiim e Acariquara & 759,15 & 2012 \\
\hline TOTAL & $\mathbf{4 2 . 8 1 7 , 2 2}$ \\
\hline
\end{tabular}

* Apenas parcialmente localizada em área urbana. APA - Área de Proteção Ambiental. RPPN - Reserva Particular do Patrimônio Natural.

FONTE: SEMMAS (2015) (http://semmas.manaus.am.gov.br/areas-protegidas/). 
Art. $6^{\circ}$ - A estratégia de qualificação ambiental do território tem como objetivo geral tutelar e valorizar o patrimônio natural do Município de Manaus, priorizando a manutenção dos espaços especialmente protegidos, a resolução de conflitos e a mitigação de processos de degradação ambiental decorrentes de usos incompatíveis e das deficiências de saneamento. $\S 1^{\circ}$ São objetivos específicos da estratégia a que se refere o caput deste artigo:

[...]

II - implantação, manutenção e valorização das unidades de conservação, dos fragmentos florestais, dos corredores ecológicos, das áreas verdes urbanas e de outros espaços relevantes de proteção de Manaus.

$[\ldots]$

Art. $7^{\circ}$ - Constituem o patrimônio natural de Manaus todos os espaços territoriais especialmente protegidos, que são as unidades de conservação, corredores ecológicos, as áreas de preservação permanente, os fragmentos florestais urbanos, as áreas verdes, o jardim botânico, assim como as praias, cachoeiras, ilhas, orlas fluviais e demais cursos d'água existentes no Município. (Grifos nossos).

Observa-se que a lei urbanística também mantém certa preocupação quanto aos espaços territoriais especialmente protegidos, como é o caso dos fragmentos florestais urbanos, porém, assim como o CAM, não estabelece instrumentos para uma efetiva proteção dos FFUs, apenas o reconhece e recomenda a sua implantação, manutenção e valorização.

Como já mencionado, um fragmento florestal urbano pode se constituir também como área verde. A Lei Complementar $\mathrm{n}^{\circ}$ 004, de 14 de janeiro de 2014, que dispõe sobre o parcelamento do solo urbano no município de Manaus, determina no seu artigo 14 que:

Art. 14 - O loteador deverá garantir, por meio do projeto de loteamento, a destinação de áreas de uso público para a implantação de equipamentos urbanos, comunitários e áreas verdes.
Aárea mínima destinada ao uso público poderá variar entre $25 \%$ (vinte e cinco por cento) e $50 \%$ (cinquenta por cento) da área total do loteamento, na forma da Lei Federal n ${ }^{\circ} 6.766$, de 19 de dezembro de 1979 (Art. 15, da Lei ${ }^{\circ}$ 004/2014). O $\S 7^{\circ}$ do artigo 16, da Lei Complementar $n^{\circ}$ 004/2014, estabelece as condições a serem consideradas para a constituição de áreas verdes na cidade de Manaus:

\begin{abstract}
Art. $16-[\ldots]$
$\S 7^{\circ}$ Poderão ser consideradas na reserva de área verde aquelas que se enquadrarem nas seguintes condições: I - associadas às faixas non aedificandi;

II - integradas ao Corredor Ecológico, previsto no Plano Diretor Urbano e Ambiental do Município de Manaus;

III - destinadas à recreação e lazer, desde que não provoquem danos à vegetação;

IV - identificadas como fragmentos florestais, conforme o disposto no Código Ambiental de Manaus.
\end{abstract}

O inciso IV reconhece como umas das possibilidades de criação de áreas verdes identificadas os fragmentos florestais, desde que identificados em conformidade com o código ambiental. No entanto, como já observado anteriormente, o código ambiental não confere ao poder executivo municipal o poder e os meios para o reconhecimento dos fragmentos florestais em si, portanto, eles surgiriam na paisagem urbana como mera consequência da delimitação de áreas verdes resultantes do parcelamento do solo urbano ou como áreas privadas não construídas no interior de imóveis urbanos.

A Lei ${ }^{\circ} 1.837$, de 16 de janeiro de 2014, que dispõe sobre as Áreas de Especial Interesse Social (AIES) previstas no Plano Diretor Urbano e Ambiental do Município de Manaus, determina outra exigência quanto às áreas verdes. De acordo com o parágrafo único do artigo $1^{\circ}$ da referida lei, as AEIS são porções do território que devem, prioritariamen- 
te, assegurar moradia digna para a população de baixa renda, por intermédio de melhorias urbanísticas, recuperação ambiental e regularização fundiária de assentamentos precários e irregulares, bem como a provisão de novas habitações de interesse social, dotadas de boa oferta de serviços, equipamentos públicos e infraestrutura urbana.

Sobre as áreas verdes em AEIS:

Art. $6^{\circ}$ - Para aprovação dos projetos de loteamentos em Áreas de Especial Interesse Social (AEIS), o órgão municipal competente exigirá dos parceladores, públicos ou privados, reserva de terrenos para implantação de equipamentos comunitários e áreas verdes, calculados em função da área total do loteamento, nas seguintes proporções:

I - 5\% (cinco por cento) para área verde, em terreno contínuo, sempre que possível se evitando a fragmentação da cobertura vegetal existente.

[...]

$\S 2^{\circ}$ As Áreas verdes e de equipamentos comunitários, deverão ser entregues ao Poder Executivo totalmente livres e desafetadas, e, no caso das áreas verdes, serem definidas fisicamente por vias ou ciclovias, de forma a facilitar sua fiscalização e acompanhamento, estando devidamente identificadas como áreas de preservação ambiental.

Outro dispositivo que merece destaque e cita os fragmentos florestais é a Lei $\mathrm{n}^{\circ} 1.838$, de 16 de janeiro de 2014, que dispõe sobre as Normas de Uso e Ocupação do Solo no Município de Manaus.

Art. $1^{\circ}$ - As Normas de Uso e Ocupação do Solo no Município de Manaus passam a vigorar na forma estabelecida nesta Lei, tendo por pressuposto a utilização do potencial de adensamento das áreas territoriais mediante os seguintes critérios:

I - a preservação das áreas de proteção e de fragilidades ambientais, incluídas as nascentes e as margens dos cursos d'água, as unidades de conservação, os fragmentos florestais e as áreas de fundo de vales.
Esse dispositivo é muito importante, pois trata especificamente da preservação dos fragmentos florestais, quando até então, segundo as leis anteriores, inexistia uma proteção jurídica específica para esses elementos da paisagem urbana. No entanto, a referida lei não supre a carência legislativa quanto à identificação, delimitação e gestão ambiental dos FFUs, a não ser quando tais fragmentos coincidam com áreas verdes, áreas de preservação permanente ou forem afetados pela criação de unidades de conservação.

Ao se falar das condutas lesivas praticadas contra os espaços territoriais especialmente protegidos, em destaque as áreas verdes, unidades de conservação e fragmentos florestais urbanos, o Código Ambiental de Manaus as classifica como infrações leve, grave, muito grave e gravíssima. Serão destacadas algumas das mais importantes:

Art. 136 - Considera-se infração leve:

$\mathrm{X}$ - permitir a permanência de animais de criação ou domésticos nas áreas verdes públicas e particulares com vegetação relevante ou florestada ou áreas de preservação permanente, que possam causar algum dano à vegetação e à fauna silvestre.

Art. 137 - Considera-se infração grave:

V - danificar, suprimir ou sacrificar árvores nas áreas verdes públicas e particulares com vegetação relevante ou florestada, nas encostas, nas praias, na orla fluvial, nos afloramentos rochosos e nas ilhas do Município de Manaus.

Art. 138 - Considera-se infração muito grave:

I - destruir ou danificar as formações vegetacionais de porte arbóreo, não consideradas de preservação permanente, nas áreas verdes públicas e particulares com vegetação relevante ou florestadas, nas encostas, nas praias, na orla fluvial, nos afloramentos rochosos e nas ilhas do Município de Manaus;

V - utilizar ou provocar fogo para destruição das formações vegetacionais não consideradas de preservação permanente, nas áreas verdes públicas e particulares com vegetação relevante ou florestadas, nas encostas, 
nas praias, na orla fluvial, nos afloramentos rochosos e nas ilhas do Município de Manaus;

XVIII - danificar árvores nas áreas de preservação permanente e nas Unidades de Conservação.

Art. 139 - Considera-se infração gravíssima:

VII - destruir ou danificar remanescentes florestais mesmo em processo de formação e demais formas de vegetação, nas áreas de preservação permanente e nas Unidades de Conservação.

Dos dispositivos destacados, observa-se que apenas o artigo 139 trata das infrações a respeito dos fragmentos florestais, considerando-se o termo "remanescentes florestais" aos quais os FFUs poderiam ser associados, no entanto, a redação do inciso reduz a aplicação de penalidade apenas aos casos em que o remanescente florestal estiver em APPs ou no interior de UCs.

Toda e qualquer atividade que envolva o uso do solo, especialmente o solo urbano, deve atender a requisitos e instrumentos que possibilitem a sua administração (Matias, 2006). A Lei Federal de n 6.766, de 19 de dezembro de 1979, que dispõe sobre o Parcelamento do Solo Urbano, estabelece em seu artigo $4^{\circ}$ alguns critérios imprescindíveis à implantação de um loteamento urbano, como os que constam em seu inciso I:

Art. $4^{\circ}$ - Os loteamentos deverão atender, pelo menos, aos seguintes requisitos:

I - as áreas destinadas a sistemas de circulação, à implantação de equipamento urbano e comunitário, bem como a espaços livres de uso público, serão proporcionais à densidade de ocupação prevista pelo plano diretor ou aprovada por lei municipal para a zona em que se situem.

Esse inciso foi dado pela Lei ${ }^{\circ} 9.785$, de 29 de janeiro de 1999, que altera a Lei do Parcelamento do Solo Urbano. Essa mesma lei determina que a legislação municipal defina, para cada zona em que se divida o território do Município, os usos permitidos e os índices urbanísticos de parcelamento e ocupação do solo, que incluirão, obrigatoriamente, as áreas mínimas e máximas de lotes e os coeficientes máximos de aproveitamento (Brasil, 1979).

Dentre uma grande mistura de termos utilizados para definir as áreas verdes urbanas, o inciso I do artigo $4^{\circ}$ da Lei ${ }^{\circ}$ 6766/1979 agrega as áreas verdes ao termo espaço livres. O termo Espaço Livre quer fornecer um conceito mais abrangente, integrando as demais expressões. Todavia, exclui de sua interpretação os espaços construídos em áreas urbanas (Matias, 2006). Para Lima e Amorim (2006), as áreas verdes podem ser consideradas como um tipo especial de espaços livres, onde o elemento fundamental de composição é a vegetação, e que elas devem satisfazer três objetivos principais: ecológico-ambiental, estético e de lazer. No entanto, como ressaltado por Dacanal et al. (2010), a legislação determina a existência de áreas públicas na malha urbana, e estas incluem espaços para circulação, equipamentos públicos de lazer, educação e saúde e espaços livres públicos em geral, mas não regulamenta sobre a qualidade dos espaços livres, que podem ou não ter vegetação arbórea com padrões de adensamento diferenciados. Dessa forma, a legislação urbanística federal não dá garantias para implantação ou conservação de florestas urbanas.

Nesse contexto, Manaus dispõe efetivamente de pelo menos 500 Áreas Verdes (AVs) existentes e distribuídas em apenas metade dos 63 bairros de Manaus (Figura 2), que somados correspondem a $80 \%$ da área urbana. Apesar de numerosas, a soma dessas áreas alcança apenas 980 ha, ou seja, 2,2\% da área total dos bairros. Em média, a área total de AVs por bairro corresponde a 27,7 ha ou $277.467,74 \mathrm{~m}^{2}$ e o número de AVs por bairro é de 15,8, em média. Os bairros Cidade Nova (276 ha, 59 AVs) e Tarumã (186 ha, 44 AVs) se destacam dos demais bairros. 


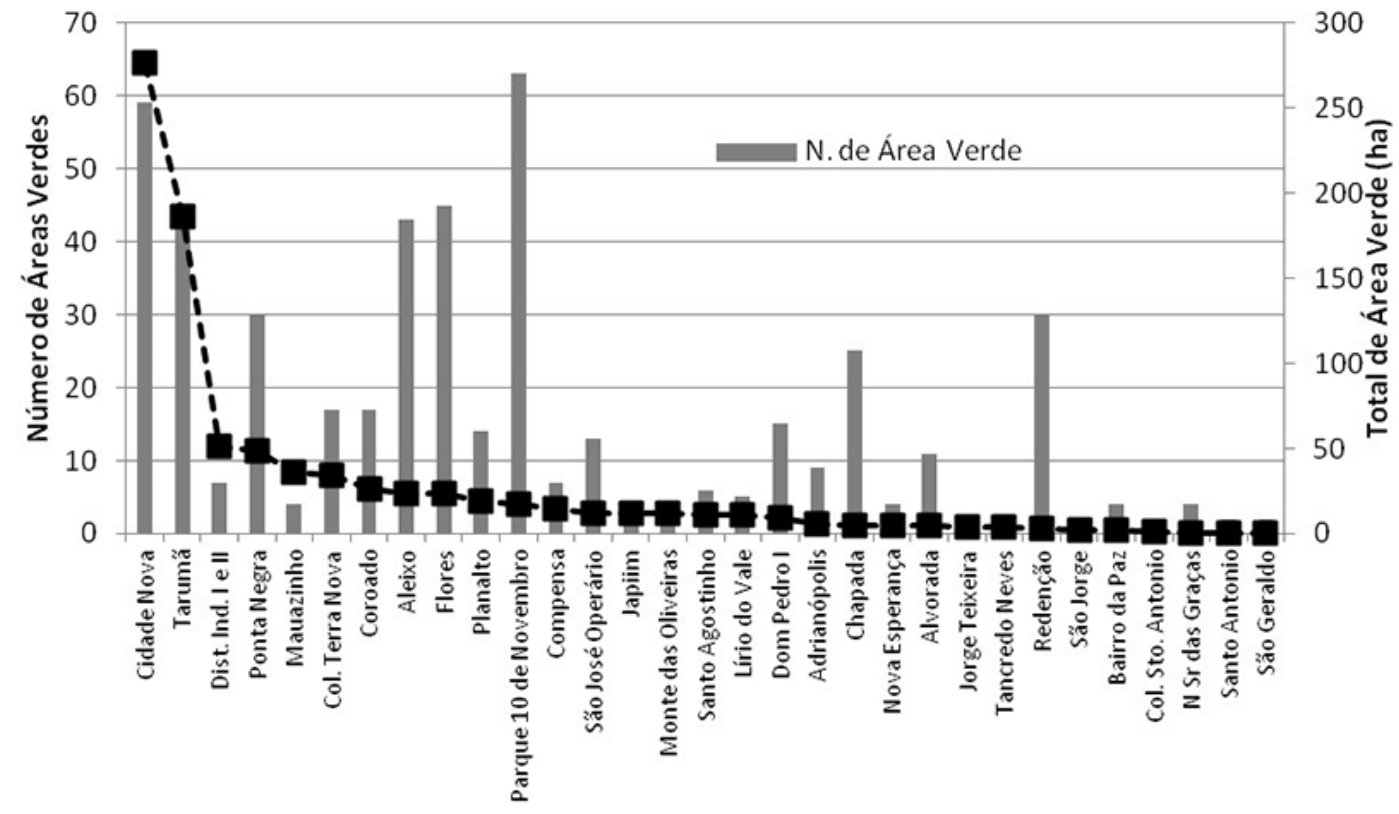

Bairros de Manaus

FIGURA 2 - Número e área total de Áreas Verdes (ha) por bairro de Manaus, Amazonas.

FONTE: Dados de Áreas Verdes - SEMMAS (2007).

Os cinco bairros de Manaus com os melhores índices de área verde (Tabela 2) apresentam resultados acima do mínimo de $15 \mathrm{~m}^{2} /$ habitante para áreas verdes públicas destinadas à recreação, sugerido pela Sociedade Brasileira de Arborização Urbana (Harder et al., 2006). Considerando-se a cidade como um todo, esse índice seria de $116 \mathrm{~m}^{2} /$ hab. para a população estimada da cidade em 2010.
Segundo o CAM, entende-se que áreas verdes e fragmentos florestais urbanos compreendem diferentes categorias de espaços especialmente protegidos, porém, vale ressaltar que um fragmento florestal urbano pode-se constituir também como uma área verde. Dessa forma, dois FFUs da cidade de Manaus foram examinados mais detalhadamente (Figuras 3 e 4). Estes são exemplos de fragmentos

TABELA 2 - Índice de Área Verde por habitante para os bairros com mais 4\% de área total em AVs na cidade de Manaus, Amazonas.

\begin{tabular}{cccc}
\hline Bairro & $\mathbf{N}^{\mathbf{0}}$ Habitantes (2010) & Total de AVs (ha) & Área verde por habitante (ha/hab.) \\
\hline Cidade nova & 121.135 & $4.760,6$ & 393,0 \\
Mauazinho & 23.560 & 734,1 & 311,6 \\
Aleixo & 20.655 & 593,5 & 287,3 \\
Planalto & 16.283 & 373,5 & 229,4 \\
Santo Agostinho & 16.593 & 157,2 & 94,8 \\
\hline
\end{tabular}

FONTE: IBGE (2010) e SEMMAS (2007). 
florestais urbanos existentes em dois bairros diferentes na cidade de Manaus.

O fragmento florestal Mundo Novo, localizado no bairro Cidade Nova, apresenta uma delimitação dada pelo município como "Área Verde", possui 4,97 ha e, na mesma porção do terreno, uma área coberta com vegetação sem destinação, que corresponde a 4,18 ha; somando as duas áreas, tem-se pelo menos 9,15 ha de área verde nessa parcela de terra (Figura 3).

O Fragmento da Ilha no bairro Planalto apresenta uma área de 12,9 ha, formada por quatro áreas verdes reconhecidas pela Prefeitura, que representa 3,5\% de área verde no bairro (Figura 4). No entanto, seu entorno apresenta resquícios de vegetação, de 8,8 ha, que não têm garantias de proteção, pois se tratam de áreas sem destinação.
Observou-se nos dois casos que apenas parte de cada fragmento florestal é considerada área verde resultante do parcelamento do solo urbano. Portanto, a área que não se insere dentro do limite demarcado não pertence ao Município e constitui-se, assim, como uma área privada ou devoluta. Considerando-se o crescente avanço da urbanização, o isolamento desses espaços naturais os torna mais valorizados e propícios às ocupações, pois não são adequadamente previstos no planejamento urbano e, assim, não recebem a proteção da lei e dos governos locais.

Previstos na legislação municipal de Manaus como espécie de espaços territoriais especialmente protegidos, os FFUs podem ser comparados aos demais espaços quanto à existência dos instrumentos legais necessários à sua efetiva proteção (Tabela 3 ).

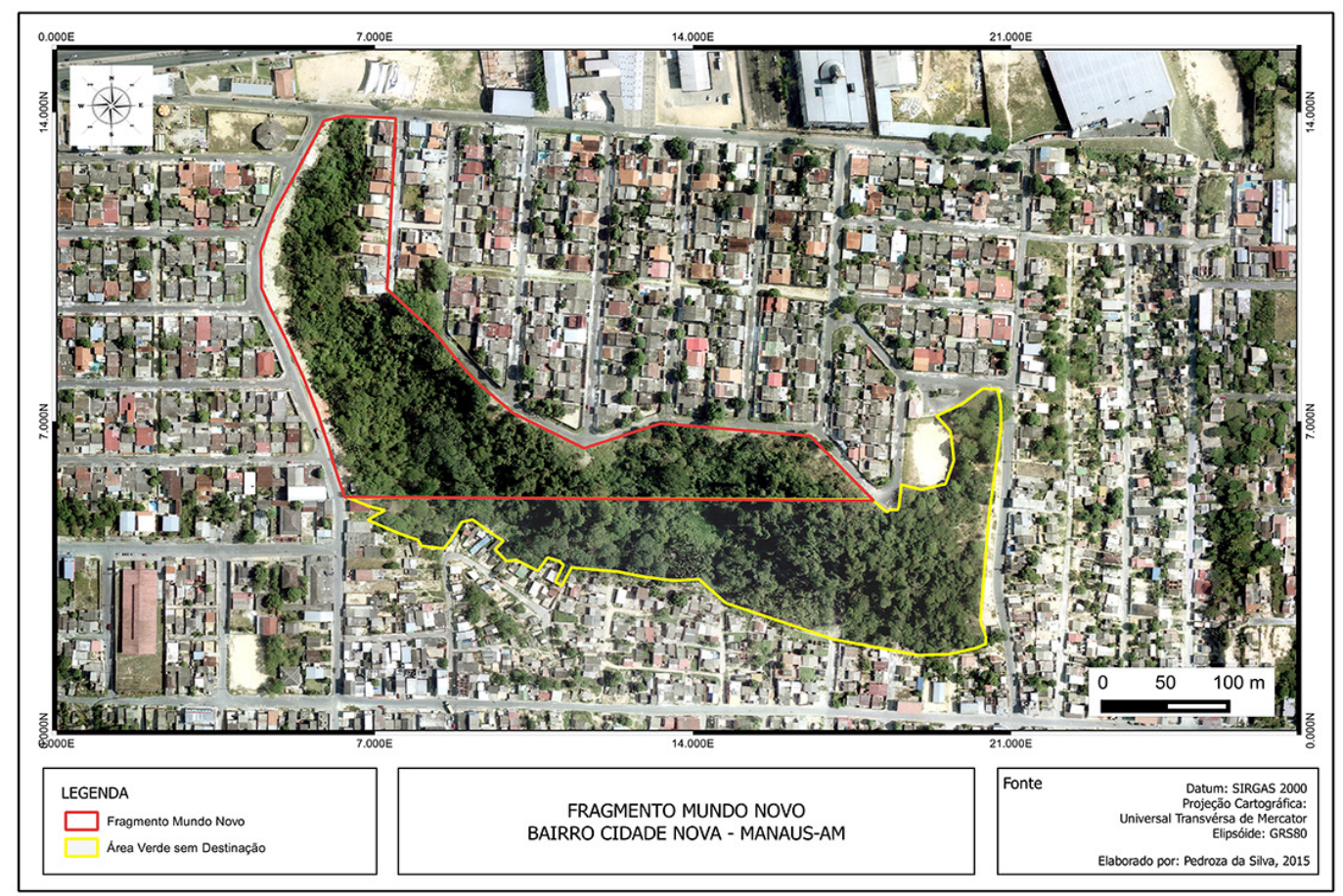

FIGURA 3 - Fragmento Mundo Novo, localizado no bairro da Cidade Nova, na cidade de Manaus. 


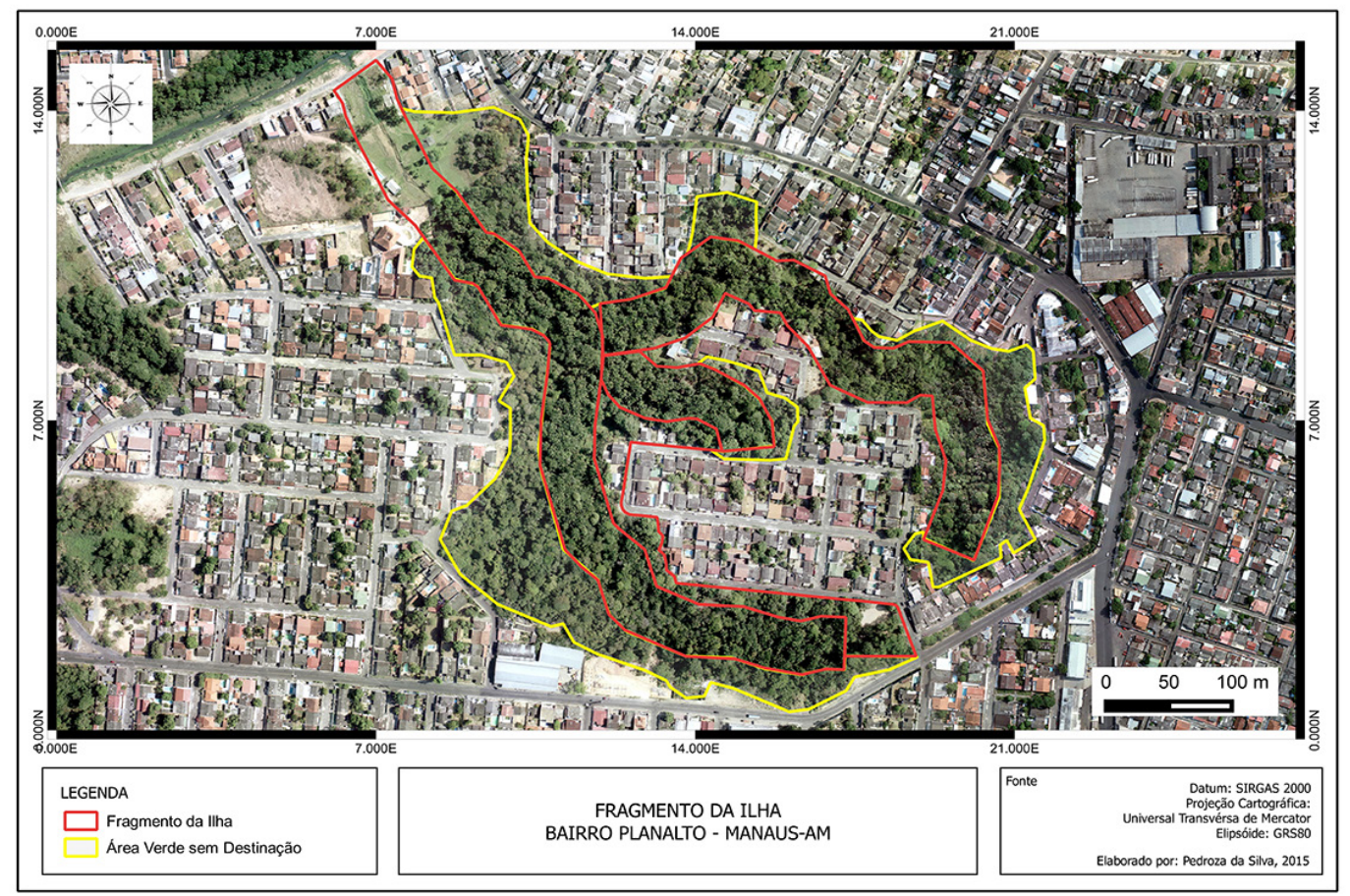

FIGURA 4 - Fragmento da Ilha, localizado no bairro Planalto, na cidade de Manaus.

TABELA 3 - Comparação da proteção jurídica dos fragmentos florestais urbanos e demais espécies de espaços territoriais especialmente protegidos.

Instrumentos jurídicos de proteção

Espécies de espaço territorial especialmente protegido

Criados por ato do Poder Público

$\begin{array}{cccc}\text { FFU } & \text { UC } & \text { AV } & \text { APP } \\ 0 & 1 & 1 & 0\end{array}$

Destinação específica de proteção de bem público: Biodiversidade e outros serviços ecossistêmicos

Destinação específica de proteção de bem público: outros bens públicos (culturais, lazer etc.)

Limites claramente estabelecidos

Restrições legais a usos determinados

Dominialidade definida

Equipe gestora local

Conselho gestor próprio

Plano de gestão (ou manejo) próprio

\begin{tabular}{llll}
0 & 1 & 1 & 1 \\
0 & 1 & 1 & 0 \\
0 & 1 & 1 & 1 \\
0 & 1 & 1 & 1 \\
0 & 1 & 1 & 1 \\
0 & 1 & 0 & 0 \\
0 & 1 & 0 & 0 \\
0 & 1 & 0 & 0 \\
\hline
\end{tabular}

FFU = Fragmento Florestal Urbano; UC = Unidade de Conservação; $\mathrm{AV}=$ Área Verde; $=\mathrm{APP}=$ Área de preservação permanente. $0=$ não atendeu ao critério; 1 = atendeu ao critério. 
Examinando-se os instrumentos que garantiriam a proteção efetiva das áreas urbanas com cobertura vegetal nativa, observou-se que o ordenamento jurídico vigente não confere nenhum deles aos FFUs. Desse modo, remanescentes florestais em áreas urbanas de Manaus podem ser facilmente destinados a outros tipos de uso do solo. Apesar de Manaus dispor de numerosas áreas verdes, estas áreas estão distribuídas em apenas metade dos bairros de Manaus e seu conjunto representa apenas 2,2\% da área total dos bairros. Entretanto, a somatória de AVs apresenta um percentual muito aquém do preconizado nas leis urbanísticas. Em média, a área total de $\mathrm{AVs}$ por bairro corresponde a 27,7 ha ou $277.467,74 \mathrm{~m}^{2}$.

Em Manaus, há fragmentos relativamente pequenos, medindo $312.000 \mathrm{~m}^{2}$, e fragmentos maiores, de $78.828 .300 \mathrm{~m}^{2}$. Os maiores fragmentos encontrados estão nos bairros da Cidade Nova e Tarumã, que correspondem a 28,1\% das áreas verdes em Manaus.

Os resultados encontrados corroboram os estudos realizados por Nascimento \& Laurance (2006), quando apontam que, apesar de numerosas, as AVs de Manaus são pequenas, formando fragmentos vegetacionais fortemente influenciados por efeitos de borda e com pouca capacidade de abrigar populações viáveis da flora e da fauna. Metade das AVs de Manaus possui área inferior a $3.186 \mathrm{~m}^{2}$, um valor abaixo do índice alcançado por cidades como Santiago, no Chile (Päcke \& Aldunce, 2010).

Damasceno et al. (2013) enfatizam que para proteger e conservar esses remanescentes florestais urbanos, contribuindo para a manutenção de suas integridades físicas e ecológicas, a criação de unidades de conservação decretada pelo poder público representa uma estratégia eficaz e, sob um regime especial de administração, seria possível realizarem-se ações para minimizar a degradação ambiental. Atualmente, no entanto, apenas 4,18\% da área urbana de Manaus estão protegidos na forma de UC. Assim como observado por Medeiros e Young (2011), em uma escala nacional, também em Manaus observa-se que a efetiva implantação das UCs ainda deixa muito a desejar, pois existem inúmeras lacunas e fragilidades no que tange à regularização fundiária, à falta de funcionários e infraestrutura básica e, principalmente, à ausência de planos de gestão.

Porém, ao analisar a legislação existente, constatou-se que as UCs seriam os únicos espaços que contariam com todos os instrumentos jurídicos de proteção. Tanto os FFUs como as APPs não são criados, mas sim reconhecidos pelo poder público em razão de suas feições paisagísticas. No entanto, ao contrário das APPs, que mesmo sem cobertura nativa continuam sendo reconhecidas como espaços protegidos, seja pela topografia (áreas de declive acentuado e topos de morros), seja por estarem localizadas nas margens dos rios, os FFUs se descontinuam enquanto espaços protegidos na medida em que, por qualquer razão, perdem a sua cobertura florestal nativa. Ao contrário das demais espécies, os FFUs não possuem área delimitada, pois não há um ato legal que estabeleça seus limites. De mesmo modo, os FFUs também não têm a proteção dada pelas restrições de usos de seus recursos ou bens ambientais, já que a legislação municipal prevê sua supressão total, desde que autorizada. Por fim, a lei não prevê uma destinação especial aos FFUs. Podem continuar sendo públicos ou privados e não são geridos de acordo com um plano de manejo (ou de gestão) executado por uma equipe local.

\section{Conclusões}

Fragmentos florestais urbanos são espaços naturais considerados recursos ambientais essen- 
ciais para a garantia da qualidade de vida nos centros urbanos. No entanto, são espaços ameaçados em decorrência da especulação imobiliária, do crescimento urbano desordenado e da degradação ambiental.

Esses espaços na esfera federal não possuem instrumentos específicos de proteção. Somente na esfera municipal é que são encontrados instrumentos legais mais específicos quanto à proteção desses espaços naturais, até mesmo o uso do termo específico "fragmento florestal urbano".

Reconhecidos apenas na legislação ambiental e urbanística no nível municipal, como o Código Ambiental, o Plano Diretor e as Leis de uso, ocupação e parcelamento do solo urbano, os fragmentos

\section{Referências}

Abreu, A. H.; Oliveira, R. J. de. Áreas verdes e municípios. Santa Catarina, 2004. Disponível em: $<$ http://www.egov. ufsc.br/portal/sites/default/files/anexos/26836-26838-1PB.pdf>.

Alvarez, I. A. Qualidade do espaço verde urbano: uma proposta de índice de avaliação. Piracicaba, Tese (Doutorado em Agronomia) - ESALQ, 2004.

Andrade, J. T. de. Gestão participativa de Unidades de Conservação no Brasil - interpretando a APA Petrópolis. Dissertação (Mestrado em Ciências Ambientais e Florestais) - Seropédica - RJ, 2007.

Arce, P. A.; Pendloski, C. J. S.; Oliveira, R. B.; Gallardo, A. L. C. F.; Ruiz, M. S. Conflitos socioambientais em unidades de conservação em áreas urbanas: o caso do Parque Tizo em São Paulo. Holos, 1(30), 75-85, 2014. Disponível em: $<$ http://www2.ifrn.edu.br/ojs/index.php/HOLOS/article/ view/1704/778>.

Carli, V. M. I. A obrigação legal de preservar o meio ambiente. Campinas: ME Editora, 2004.

Brandão, J. C. L. Direito Ambiental: o Amazonas em juízo. Manaus: Editora da Amazônia, 2012. 252 p. florestais urbanos são tratados como tipos genéricos de espaços protegidos para os quais não são previstos mecanismos operacionais de delimitação e regime especial de proteção e de gestão pública.

Considerando-se a grande importância da permanência dos fragmentos florestais na paisagem urbana, estes deveriam receber uma proteção jurídica mais efetiva. Percebe-se que estes espaços apenas terão a devida proteção legal se estiverem constituídos como unidades de conservação de acordo com a lei do SNUC (federal) ou do SEUC (estadual), pois assim seriam administrados como espaços territoriais criados com limites e dominialidade claramente definidos, destinação e gestão local.
Brandão, J. C. L. Novo Código Florestal Brasileiro: anotações à Lei 12.651/12 com as alterações da Lei 12727/12. Curitiba: Juruá Editora, 2012. 314 p.

Brasil. Lei $n^{\circ}$ 6.766, de 19 de dezembro de 1979. Dispõe sobre o Parcelamento do Solo Urbano e dá outras Providências. Brasília: DOU de 20.12.1979.

Brasil. Lei $n^{\circ} 6938$, de 31 de agosto de 1981. Dispõe sobre a Política Nacional do Meio Ambiente, seus fins e mecanismos de formulação e aplicação, e dá outras providências. Brasília: DOU de 2/9/1981.

Brasil. Constituição da República Federativa do Brasil de 1988. Brasília: DOU de 5/10/1988.

Brasil. Lei $n^{\circ}$ 9.785, de 29 de janeiro de 1999. Altera o Decreto-Lei no 3.365, de 21 de junho de 1941 (desapropriação por utilidade pública) e as Leis $\mathrm{n}^{\circ} \mathrm{s} 6.015$, de 31 de dezembro de 1973 (registros públicos) e 6.766, de 19 de dezembro de 1979 (parcelamento do solo urbano). Brasília: DOU de 1.2.1999 e retificado em 4.2.1999.

Brasil. Lei $n^{\circ}$ 9.985, de 18 de julho de 2000. Institui o Sistema Nacional de Unidades de Conservação. Brasília: DOU de 19/7/2000. 
Brasil. Lei $n^{\circ} 10.257$, de 10 de julho de 2001. Regulamenta os artigos 182 e 183 da Constituição Federal, estabelece diretrizes gerais da política urbana e dá outras providências. Brasília: DOU de 11.7.2001 e retificado em 17.7.2001.

Brasil. Lei $n^{0} 12.651$, de 25 de maio de 2012. Dispõe sobre a proteção da vegetação nativa; altera as Leis $n^{\circ} \mathrm{s} 6.938$, de 31 de agosto de 1981, 9.393, de 19 de dezembro de 1996, e 11.428, de 22 de dezembro de 2006; revoga as Leis $\mathrm{n}^{\circ} \mathrm{s}$ 4.771, de 15 de setembro de 1965, e 7.754, de 14 de abril de 1989, e a Medida Provisória n ${ }^{\circ}$ 2.166-67, de 24 de agosto de 2001; e dá outras providências. Brasília: DOU de 28.5.2012.

Dacanal, C.; Labaki, L. C.; Silva, T. L. M. da. Vamos passear na floresta! O conforto térmico em fragmentos florestais urbanos. Ambiente Construido, 10(2), p. 115132, 2010. Disponível em: <http://www.scielo.br/pdf/ac/ v10n2/a08.pdf $>$.

Damasceno, C. M.; Júnior, W. B. de S.; Pereira, H. dos S.; Silva, N. M. da. Fragmentos florestais como áreas protegidas em uma microbacia urbana na Amazônia. In: Anais do VI Seminário Brasileiro sobre Áreas Protegidas e Inclusão Social - I Encontro Latino-americano sobre Áreas Protegidas e Inclusão Social - SAPIS. Belo Horizonte, 2013. Disponível em: $<$ http://www.academia.edu/4853021/ ANAIS_DO_VI_SEMIN\%C3\%81RIO_BRASILEIRO_SOBRE_\%C $3 \% 81 \mathrm{REAS}$ _PROTEGIDAS_E_ INCLUS\%C3\%83O_SOCIAL_-_VI_SAPIS >

Dos Anjos, H. D. B. Efeitos da fragmentação florestal sobre as assembleias de peixes de igarapés da zona urbana de Manaus, Amazonas. Manaus, Dissertação (Mestrado em Biologia de Água Doce e Pesca Interior) - INPA, 2007.

Filho, A. F. do N. O corredor ecológico urbano do Min$d u$ : ações do Poder Público Municipal e participação da coletividade. Manaus, Dissertação (Mestrado em Direito Ambiental) - UEA, 2011.

Freitas, R. E. de; Ribeiro, K. C. C. Educação e percepção ambiental para a conservação do meio ambiente na cidade de Manaus - uma análise dos processos educacionais no Centro Municipal de Educação Infantil Eliakin Rufino. Revista Eletrônica Aboré, 3, 2007. Disponível em: <http:// www.revistas.uea.edu.br/old/abore/artigos/artigos_3/Rafael\%20Estrela\%20de\%20Freitas.pdf>.

Freitas, V. P. de. A Constituição Federal e a efetividade das normas ambientais. São Paulo: Revista dos Tribunais, 2002.
Gontijo, J. C. F. Uso dos fragmentos florestais urbanos da cidade de Manaus - AM. Manaus, Dissertação (Mestrado em Ciências do Ambiente) - UFAM, 2008.

Harder, I. C. F.; Ribeiro, R. C. S.; Tavares, A. R. Índices de área verde e cobertura vegetal para as praças do Município de Vinhedo, SP. Revista Árvore, 30(2), 277-282, 2006. Disponível em: <http://www.scielo.br/pdf/rarv/v30n2/ a15v30n2.pdf $>$.

IBGE. Diretoria de Pesquisas, Coordenação de População e Indicadores Sociais. Censo da população residente com data de referência 2010. Disponível em: $<\mathrm{http} / /$ www.cidades.ibge.gov.br/xtras/perfil.php?lang=\&codmun $=130260>$. Acesso em: junho de 2015.

IBGE. Manual técnico da vegetação brasileira: sistema fitogeográfico, inventário das formações florestais e campestres, técnicas e manejo de coleções botânicas, procedimentos para mapeamentos. 2. ed. Rio de Janeiro: IBGE - Instituto Brasileiro de Geografia e Estatística, 2012. 275 p.

Lima, V.; Amorim, M. C. de C. T. A importância das áreas verdes para a qualidade ambiental das cidades. Revista Formação, 13, 139-165, 2006. Disponível em: <http:// revista.fct.unesp.br/index.php/formacao/article/viewFile/835/849>.

Manaus. Lei $n^{\circ} 605$ de 24 de julho de 2001. Institui o Código Ambiental do Município de Manaus e dá outras providências. DOM de 24.07.2001

Manaus. Lei Complementar $n^{\circ}$ 002, de 16 de janeiro de 2014. Dispõe sobre o Plano Diretor Urbano e Ambiental do Município de Manaus e dá outras providências. Manaus: DOM de 16.01.2014a.

Manaus. Lei Complementar $n^{\circ}$ 004, de 16 de janeiro de 2014. Dispõe sobre o Parcelamento do Solo Urbano do Município de Manaus e dá outras providências. Manaus: DOM de 16.01.2014b.

Manaus. Lei $n^{\circ}$ 1.837, de 16 de janeiro de 2014. Dispõe sobre as Áreas de Especial Interesse Social previstas no Plano Diretor Urbano e Ambiental do Município de Manaus e dá outras providências. Manaus: DOM de 16.01.2014b.

Manaus. Lei $n^{0} 1.838$, de 16 de janeiro de 2014. Dispõe sobre Normas de Uso e Ocupação do Solo no Município de Manaus e estabelece outras providências. Manaus: DOM de 16.01.2014d. 
Maquiné, D. B. Cidades sustentáveis e o princípio da função ambiental da cidade. Manaus, Dissertação (Mestrado em Direito Ambiental) - UEA, 2006.

Matias, J. O. Áreas verdes urbanas como elemento da cidade sustentável. Manaus, Dissertação (Mestrado em Direito Ambiental) - UEA, 2006.

Medeiros, R; Young, C. E. F. Contribuição das unidades de conservação brasileiras para a economia nacional: Relatório Técnico UNEP, Brasília: UNEP $\square$ WCMC, 2011.20p.

Meira, J. de C. Direito Ambiental. Informativo Jurídico da Biblioteca Ministro Oscar Saraiva, 19(1), 11-23, 2008. Disponível em: $<$ http://www.stj.jus.br/publicacaoinstitucional/ index.php/informativo/article/viewArticle/50>.

Melo A. G. C.; Carvalho, D. A.; Castro, G. C.; Machado, E. L. M. Fragmentos Florestais Urbanos. Revista Cientifica Eletrônica de Engenharia Florestal, 17(1), 2011. Disponível em: $<$ http://faef.revista.inf.br/imagens_arquivos/arquivos_destaque/Ozb1mN5plNQ3cZw_2013-4-29-11-34-29. pdf>.

Minks, V. A rede de design verde urbano - uma alternativa sustentável para megacidades? Revista LABVERDE, 6,
121-141, 2013. Disponível em: <http://www.revistas.usp. br/revistalabverde/article/view/81089>.

Nascimento, H. E. M.; Laurence, W. F. Efeitos de área e de borda sobre a estrutura florestal em fragmentos de floresta de terra-firme após 13-17 anos de isolamento. Acta Amazônica, 36(2), 183-192. 2006. Disponível em: <http://www.scielo. br/pdf/aa/v36n2/v36n2a08.pdf>.

Päcke, S. R.; Aldunce, I. M. F. Distribución, superficie y accesibilidad de las áreas verdes en Santiago de Chile. CEURE, 36, 89-110(109), 2010. Disponível em: <http:// www.scielo.cl/pdf/eure/v36n109/art04.pdf>.

Pereira, P. F.; Scardua, F. P. Espaços territoriais especialmente protegidos: conceito e implicações jurídicas. Ambiente \& Sociedade, 11(1), 81-97, 2008. Disponível em: $<$ http://www.scielo.br/pdf/asoc/v11n1/06.pdf $>$.

PMM - Prefeitura Municipal de Manaus. Disponível em $<$ http://semmas.manaus.am.gov.br/areas-protegidas/>. Acesso em: junho de 2015.

Ramos, S. P. A proteção jurídica dos fragmentos florestais urbanos. Manaus, Dissertação (Mestrado em Direito Ambiental) - UEA, 2005. 